Results Results showed that the majority of farmers (81.4\%) used chemical pesticides in the production of cashew, but only $11 \%$ of them have been trained to safe use of pesticides. In addition, 16 of the 35 farmers (45.7\%) had individual protection equipment appropriate. Thus, 10 cases of acute intoxication were reported during the application of pesticides. Glyphosate isopropylamine salt was responsible for 5 cases of poisoning, while $2.4 \mathrm{D}$ amine salt caused 3 cases. However, $35 \%$ of these pesticides were not homologated for their use in cashew farming in Côte d'Ivoire.

Conclusion Pesticide use was a real handicap for the sustainability of the cashew farming in Côte d'Ivoire. High use of non-homologated pesticides and absence of farmers training in safe use of pesticides could be cause occupational hazards, possibly environmental pollution and affected cashew nut safety.

\section{A PESTICIDE EXPOSURE STUDY USING 24-HOUR BIOMONITORING AND DERMAL SAMPLING TO DETERMINE TOTAL UPTAKE AND THE ROUTES OF EXPOSURE}

\begin{abstract}
${ }^{1}$ Alison Connolly*, ${ }^{2}$ Kate Jones, ${ }^{3}$ Karen S Galea, ${ }^{3}$ Ioannis Basinas, ${ }^{2}$ Laura Kenny, ${ }^{4}$ Padraic McGowan, ${ }^{1}$ Marie Coggins. ${ }^{1}$ Centre for Climate and Air Pollution Studies, School of Physics, National University of Ireland, Galway, Ireland; ${ }^{2}$ Health and Safety Laboratory (HSL), Harpur Hill, Buxton, UK; ${ }^{3}$ Centre for Human Exposure Science (CHES), Institute of Occupational Medicine (IOM), Edinburgh, UK; ${ }^{4}$ rrish Commissioners for Public Works, Jonathon Swift Street, Trim, Co Meath, Ireland
\end{abstract}

\subsection{6/oemed-2018-ICOHabstracts. 1327}

Introduction A pilot exposure assessment study using biomonitoring was conducted in Ireland to determine the likelihood of exposure to pesticides among amenity horticulturalists. A spot sampling approach was employed of workers using pesticides, had urinary pesticide concentrations in post-work samples with a geometric mean (geometric standard deviation) of 0.66 (1.11) $\mu \mathrm{g} \mathrm{\textrm {L } ^ { - 1 }}$ for glyphosate and 0.29 (1.69) $\mu \mathrm{g} \mathrm{L}^{-1}$ for fluroxypyr. The study showed a potential for pesticide exposure during horticulture amenity work, higher than average environmental exposure levels and warranted further investigation.

Methods In 2017, an exposure assessment study involving 24 hour biomonitoring will take place to evaluate pesticide exposure among these workers. Workers will be grouped into four similar exposure groups based on application method and active ingredient used, glyphosate or fluroxypyr. Three urine samples will be collected for each task, a sample before the task begins, a sample within one hour of the task completion and a following morning void. The potential routes of exposure, will be examined through the collection of additional dermal, glove and potentially contaminated object wipe samples. Dermal wipes of the hands and the perioral region will be taken before and after the task and glove analysis will be conducted. Detailed contextual information will be collected by the researcher to support all samples collected.

Results The biomonitoring results will indicate the extent of pesticide uptake for each task. Correlation between the dermal and biomonitoring samples will be investigated to explore the contribution of dermal exposure. The perioral and the contaminated object wipes alongside the contextual information will be used to determine the potential exposure from inadvertent ingestion.
Discussion This study will provide a comprehensive biomonitoring dataset describing amenity horticultural user's exposure to glyphosate and fluroxypyr and the contribution of dermal and inadvertent ingestion routes on total body burden of pesticides.

\section{WORK-RELATED DISEASES AMONG FARMERS IN NORWAY: WHAT DO THE DOCTORS REPORT TO THE LABOUR INSPECTORATE REVEAL, AND WHAT THEY MISS?}

${ }^{1} Y$ Samant, ${ }^{2} \mathrm{HM}$ Gravseth, ${ }^{3} \mathrm{O}$ Aas, ${ }^{1} \mathrm{R}$ Ekle, ${ }^{1} \mathrm{~T}$ Strømholm. ${ }^{1}$ Norwegian Labour Inspection Authority, Norway; ${ }^{2}$ National Institute of Occupational Health, Norway; ${ }^{3}$ St. Olav's Hospital, Division of occupational medicine, Norway

\subsection{6/oemed-2018-ICOHabstracts. 1328}

Introduction Doctors in Norway report work-related diseases to the Labour Inspection Authority as required by the Working Environment Act. These reports make the basis for the labour inspectorates registry for work-related diseases (RAS). The purpose of this study is to highlight the lack of reliable data with regards to work-related diseases among Norwegian farmers which hinders our preventive efforts.

Methods Data as they concern the occupation 'farmers' were extracted from RAS for the period 2005-2017. The data among others included variables pertaining to demographics, occupational exposures, diagnosis, year of reporting, and the type of doctor who reported the disease. We performed descriptive analysis on the extracted data to obtain frequency, and percentage distribution of the data. We plan to calculate incidence rates; however, it has been difficult to find a reliable denominator for such computations.

Result In the period 2005-2017, 616 cases of work-related diseases among farmers were reported. On average 44 reports of work-related disease among farmers were reported to the Labour Inspectorate annually. 95\% of the reported cases were farmers under the age of 67 years. Hearing loss made up about $60 \%(n=368)$ of all the cases followed by respiratory diseases that make up $19 \%(n=116)$ of all cases. Only a few cases are attributed to other diagnosis groups like skin diseases, musculoskeletal- and psychological disorders.

Discussion The doctors report on work-related diseases among farmer's reveal that hearing loss is still a major challenge. Some of these data are being applied for preventive actions. Having said that, we know from research studies and selfreported data that farmers are exposed to among others dust, gas, pesticides, infectious materials. They work long hours in difficult postures. However, RAS data is missing a large number work-related diseases among the Norwegian farmers which is hindering effective prevention.

\section{HEALTH EFFECTS OF PESTICIDES: PROBLEMS TO SOLUTIONS}

${ }^{1}$ Claudio Colosio, ${ }^{2}$ Gert van der Laan, ${ }^{3}$ Hanifa Denny. ${ }^{1}$ Department of Health Sciences of the University of Milan and International Centre for Rural Health of the ASTT Saints Paolo and Carlo Hospital, Milan, Italy; ${ }^{2}$ Foundation Learning and Developing Occupational Health, PE Leusden, Netherlands; ${ }^{3}$ Diponegoro University, Semarang, Indonesia

10.1136/oemed-2018-ICOHabstracts. 1329 
Aim of special session Main problems related to pesticide use and abuse in the world will be addressed, with a particular effort for identifying possible solutions.

Pierluigi $\mathrm{Cocco}^{3}$, Erik Jors ${ }^{4}$, Angelo Moretto ${ }^{5}$, Leslie London $^{6}$, El Yamani Mounia ${ }^{7}$, Francesca Larese Filon ${ }^{8}$, Susan Brumby $^{9}$, Claudio Colosio ${ }^{1}$, Silvia Fustinoni ${ }^{10}$, Hanifa Denny ${ }^{2}$

${ }^{1}$ Department of Health Sciences of the University of Milan and International Centre for Rural Health of the S. Paolo Hospital, Italy

${ }^{2}$ Foundation Learning and Developing Occupational Health, Leusden, The Netherlands

${ }^{3}$ Diponegoro University, Semarang, Indonesia

${ }^{4}$ Department of Medical Sciences and Public Health, University of Cagliari, Cagliari, Italy

${ }^{5}$ Department of Occupational and Environmental Health, Odense University Hospital, Odense, Denmark

${ }^{6}$ Department of Biomedical and Clinical Sciences, University of Milan, Milan, Italy

${ }^{7}$ School of Public Health and Family Medicine, University of Cape Town, Cape Town, South Africa

${ }^{8}$ Santé publique France, Direction Santé Travail, St Maurice, France

${ }^{9}$ Unit of Occupational Medicine, Dept. of Medical Sciences, University of Trieste. Trieste, Italy

${ }^{10}$ National Centre for Farmer Health, Western District Health Service, Hamilton VIC, Australia

\section{9a DEVELOPMENT OF NEW TOOLS FOR BRINGING PESTICIDE RISK ASSESSMENT IN THE SMALL SIZE ENTERPRISES AND IN THE DEVELOPING WORLD}

C Colosio. Department of Health Sciences of the University of Milan and International Centre for Rural Health of the S. Paolo Hospital, Italy

\subsection{6/oemed-2018-ICOHabstracts.1330}

The role of pesticides in the modern society has been strengthened by the need for higher yield in food production and the ongoing battle against vector borne diseases in public health. Nevertheless, the toxicity of these chemicals is not fully specific to target organisms, thus posing a potential health threat to humans. In this frame, risk assessment and management are fundamental. In the occupational settings, variability of meteorological conditions, use of different concentrations of highboy variable mixtures, and significant variations in the application times and modalities make this task very complicated, underlining the need for novel approaches for conducting 'in field' preventive activities. New developments in pesticide risk assessment should start from the fact that the amount of information collected during the process of authorisation of new active ingredients is unique, similar to that available for pharmaceutical products, and that this significant amount of information is scarcely used in the post market risk assessment activities. In this light, a possible way forward for pesticide risk assessment is represented by a better exploitation of these data, in approaches with variable levels of complexity; the simplest, is the evaluation of the adherence of the use scenario under evaluation with the one checked and approved in the authorisation process and synthesised in the good agricultural practices. Other parameters such as
Acceptable Operator Exposure Level (AOEL), acute reference dose (ArD) as well data regarding skin absorption, metabolism and relevant metabolites in animals can find use in the realisation of models adequate to estimate the dose and the risk without doing analysis, as well as to calculate provisional biological exposure indices, defining the dose supposed to be excreted in a subject exposed at the AOEL level. This can be done conducing real-life field studies to usable refine and validate the risk hypotheses generated through modelling.

\section{9b SAFE USE OF PESTICIDES AMONG TRADITIONAL FARMERS IN JAVA INDONESIA}

Hanifa M Denny*, Bina Kurniawan*, Siswi Jayanti*, Ari Suwondo*. Diponegoro University, Semarang, Indonesia

\subsection{6/oemed-2018-ICOHabstracts. 1331}

Introduction The use of pesticides in the Indonesian vegetable farming is common. The conventional and traditional methods of pesticides used are mostly dangerous nor safe. This study investigated the impact of health promotion intervention on safe use of pesticides among farmers in Sumowono Village, Semarang District, Indonesia.

Methods The researchers conducted a multi-year's approach to conduct a training on safe use of pesticides as a health promotion intervention. In 2013, the researcher approached the community health centre staff to gather their understanding on unsafe pesticides used among farmers. The researchers made a collaboration with one nurse and one midwife to be part of the field coordinator team. The actual training session was conducted in 2015.

Results The farmer's community agreed with the idea of participating in the Focus Group Discussion and training on safe use of pesticides. Selected farmers of 136 persons participated in the training. It was tailored to find a solution on un-safe use of pesticides according to participants daily practices.

Knowledge and attitude of pesticides use were improved after joining the training session. The adoption of expected behaviour on safe use of pesticides was evaluated one year after the training. A significant behaviour change was seen on drinking water after working with pesticides. In addition, the practice of taking a painkiller medicine was no longer available since the training participants gained knowledge on dehydration, pesticides intoxication, and the benefit of water intake to expedite the excretion of pesticides from the body. Conclusion Health promotion interventions involving the local health workers were effective. A three years approach in health promotion delivery was useful in strengthening to the adoption of the expected healthy behaviours.

\section{9c CANCER AND OTHER CHRONIC DEGENERATIVE DISEASES FOLLOWING LONG TERM EXPOSURE TO PESTICIDES}

Pierluigi Cocco. Department of Medical Sciences and Public Health, University of Cagliari, Cagliari, Italy

10.1136/oemed-2018-ICOHabstracts. 1332 